\title{
Virtual Organization Theory: Current Status and Demands
}

\author{
Americo Nobre G.G. Amorim \\ Rua do Espinheiro, 854-Recife-PE \\ 52020-020,Brazil \\ americoamorim@gmail.com
}

\begin{abstract}
The intense use of Information technologies in various functions caused many changes on organizations. The utmost in terms of technology usage are the virtual organizations: operating with virtual processes globally, by means of networks. This paper has the objective to present organizational theories and try to identify aspects which can be applied to virtual organizations and the ones which need more profound research. The main contribution of this work is to start the creation a strong theoretical approach for modeling these organizations. Managers working in this kind of companies might also benefit from a better understanding when designing and managing virtual organizations.
\end{abstract}

\section{Introduction}

During the last three decades, information technologies (IT) and telecommunications have been improved and spread worldwide. From small firms to multinational corporations, it became present in almost all management areas such as marketing, sales, human resources and controlling.

New technologies emerged during the nineties such as multimedia and virtual reality, and companies started to use them in activities such as product development, advertising and communication. In the same period, Internet connections became available to general public. This is the context where virtual organizations emerge and began to take place.

Several kinds of organizations labeled as been "virtual" or "digital" started to call attention in the media and academic circles during the so-called "dot.com bubble" period. Researches in fields such as management, economics and computer science argue that virtual organizations have different characteristics than "traditional" ones. That comes from their virtuality in terms of competing globally without geographical restrictions. Several studies focused on conceptualizing and defining the main business activities of virtual organizations, but some significant dimensions remain 
unclear. Knowledge about the influences of virtuality in organizational dimensions is one of the most important issues to workers and researchers.

The objective of this paper is to discuss and bring to attention the theoretical issues that remain uncovered by literature and that need deeper research. This is done by confronting virtual companies with organizational theories, trying to identify points of convergence and issues that remain unclear. It's expected that this approach will reveal when classic management literature is still useful and issues for future research. The paper first presents a short review on organizational theories, discusses the main issues of virtual organizations and finally confronts them.

\section{Organizational Theories}

One of the main foundations to organization theories was the Bureaucracy [23]. It states that firms should be conducted by a rational-legal authority system. It stated that managers should create clear rules stating the tasks, responsibilities and requirements for each job position. Merton [17] argued that excessive bureaucratic rules and control can lead to serious dysfunctions.

The first scientific approaches to management were the studies of "Classic Management" $[8,20]$. In their view, the organizations should be structured with work division, grouping common activities in departments and workers should be controlled closely by their superiors. Fayol [8] defined the four most important managerial activities: planning, organizing, leading and controlling. Workers are perceived as Homo Economicus taking rational decision to maximize their gains. In this context, the most evident motivational tool was the financial payment (wages).

This view is followed by the Human Relations Movement, with its psychological background applied to Homo Social [15]. They thought that workers were affected by complex needs such as affiliation in informal groups, affectivity and sociability. Motivation could be achieved by fulfilling personal needs such as the wish to be recognized. Organizations should be designed in a way to assure that workers interests are reflected in managerial objectives, providing psychosocial incentives.

The motivation and leadership theories considered workers with complex needs such as self-actualization and esteem $[14,16]$. Complex man would have autonomous thinking, making predictions about behavior almost impossible. Maslow's [14] work about the hierarchy of human needs oriented managers about how to act in relation to their various types of workers. McGregor [16] named the classic management as "Theory X", considering that it didn't inspire satisfaction among workers. In his "Theory Y", workers were naturally dedicated and engaged. Managers should organize resources for production, stimulating the participation of workers in decision processes and inspiring responsibility behaviors.

One of the outcomes from McGregor theories is Argyris [2] work. He argued that there are two types of organizations: Organization " $\mathrm{A}$ " with centralized and hierarchized decision processes and organization " $B$ " in which workers perform relevant role in decision making. "A" workers are specialized and have low knowledge about the organizational activities unrelated to their work. Organization 
"B" offers a more clear vision about its information and objectives, making workers aware about medium and long-term plans. That makes them better informed and active in decision processes.

Structuralist approaches [10] tend to defend that the objectives and preferences of dominant groups are expressed in the bureaucratic rules of the organizations. Change resistance and conflicts take place by unprivileged groups. They could be co-opted by the dominant ones to gather support for their objectives. Structuralists see man as "organizational", flexible and resistant to frustrations. That leads to a strong need for self accomplishment in several social roles taken, which is achieved by formulating goals that will become reality by politically actions and work.

All those theories are related to internal issues of the organizations. The relationship of firms with the environment emerged with the systems theory. Katz and Kahn [12] used the open-system perspective to define the main characteristics of organizational change of energy, mapping inputs, transformation, output and renewed input.

Emery and Trist [7] stated that organization structure should be adapted to the environment needs and roles performed. In turbulent and complex markets organizations should give more attention to benefits offered to highly qualified workers. In stable markets, organizations can have simpler structure, employing less effort on gathering and processing information.

Reeves and Woodward [24] related production types with organizational characteristics. Process production requires horizontal structures and there are a lot of qualified professionals that control parts of the process. In mass-production the complexity is lower and there is a more apparent hierarchy. In unitary or projectbased production, horizontal structure is present together with direct control.

Burns and Stalker [4] created two models for describing organizations: mechanistic and organic. Mechanistic organizations are traditional and suitable to competitively and technologically stable environments. Workers are specialized and have well defined roles, the hierarchy is vertical, decision making is centralized and bureaucratic controls are dense. Organic organizations are well suited for turbulent environments with intense competition and technological innovations. They are characterized by multi-functional teams where worker roles are dynamic and there aren't specific tasks. Control is decentralized and autonomy in decision making is strengthened. Workers competences are the main competitive characteristic of organic organizations.

After this brief review on the evolution of organizational thinking, the focus will change to the analysis of virtual organizations, looking for intersections between concepts and characteristics between this kind and the organizational theory.

\section{Virtual Organizations}

Virtual organizations (VO) emerged at the end of 1990s with the dotcom companies and the consolidation of internet usage among traditional companies. In organizational theory, one of the first published works about VO was Davidow and 
Malone's [6]. Virtual organization was then used by several researchers with different meanings such as outsourcing, telework and others.

Goldman, Nagel e Preiss [9] argued that a virtual organization is an opportunistic alliance of core competences to fulfill a specific demand. Davidow and Malone [6] agree that $\mathrm{VO}$ conduct common activities trough series of relationships.

Other authors seek to define $\mathrm{VO}$ in terms of processes that characterize their activities. VO strategic approach would concentrate in creating and developing intellectual resources through several relationships [21]. Virtuality could be seen as an organizational dimension. Traditional companies could apply virtual configurations in strategic approaches. Mowshowitz [19] sees VO as means to manage organizations by key-activities such as the identification of demands that can be virtually fulfilled, search entities that can supply those demands and dynamic associate entities to the demands according to certain criteria.

Authors like Hale and Whitlaw [11] understand VO as companies that are in constant need of changing. The ability to change processes to achieve goals would be the essence of those organizations. VO can still be described as those that massively adopt technologies such as networks that reduces their geographic, time and information restrictions. For this paper, we will adopt the definition that a $\mathrm{VO}$ is a systemic arrange of entities (mans, autonomous agents, organizations, systems) trying to dynamically integrate, by IT means, demands and resources for their fulfillment with strategically defined operational rules [5].

\section{Virtual Organizations and Organization Theories}

Having emerged almost 100 years after the "classic management" period, VO exists in a completely different set in terms of economical, technological and social issues. VO seem to differ in many aspects: task-based work division was replaced by multiroles approaches; centralized decision making changed to certain levels of autonomy for groups of workers and highly vertical hierarchy seem to have been cut down. Therefore, Homo Economicus is outdated and incompatible with VO workers.

The human relations approach represents one step further toward virtual organizations. However it's ingenuous to think that VO, highly based on knowledge and qualified professionals, don't recognize the importance of informal organization. On the contrary, there are evidences that VO deliberately promote its workers to interact and create informal relations. Additional types of ties to the organization are especially important in environments that present high turnover rates because of the competition among companies to hire qualified workers. The control and exercise of power among workers doesn't seem to be the main concern. Informal relations tend to be perceived as means for creating cohesive groups that can act independently. That said, Homo social conception is inadequate.

Virtual organizations also seem to act different than what is stated by bureaucracy theory. Explicit and stable formalization of job positions seems to be incompatibly with the flexibility requirements for VOs and their workers. Hierarchy also seems to be mutable, mainly when the VO is structured in autonomous teams assigned to perform certain tasks that change constantly. 
The rational-legal system seems to be noted in VOs at a different level. It seems that transparency and governance mechanisms drive VOs rational-legal system. Horizontal hierarchy put managers and workers closer, making it easy to develop personal relations. Unfavorable managerial decisions to workers can't be blamed on higher and far away hierarchical levels, which echo some of Blau's [3] ideas.

Satisfaction and motivation of workers are vital to VOs. Highly qualified workers are valued and demanded by firms, which makes unemployment smaller than non-qualified positions. In some fields there is even a deficit of professionals [1]. The possibility of changing to other company tends to make workers to look forward higher levels of Maslow's [14] motivation such as esteem and selfactualization. Lower levels such psychological and safety seems to be fundamentals that should be presented. That said, it's clear that McGregor's X Theory [16] is completely out of question. VOs are closer to $\mathrm{Y}$ Theory, where workers are perceived as creative, responsible and hard workers.

These characteristics of VOs workers can place them as Argyris [2] type B. Information technology can be crucial to guarantee effective participation in decision processes, integrated organizational view and the flow of relevant information for workers. Regarding to power and authority, VOs can be perceived as adhocracies [18]. Even when teams of workers can take decisions related to their work, it's unclear if they can influence strategic decisions. The idea that dominant groups interests are expressed in organization rules [10] doesn't appear to fit straight. Dominant interests may be propagated more by influence in behavior, strategy and organizational policies.

To understand and work with VOs, systems perspective seems to be one of the best fits. In VOs, many links [13] between groups and systems, in operational and managerial levels, are provided by non-human entities, like information technologies (expert systems, artificial intelligence). It is reasonable to say that can lead to higher human interactions in strategic levels. That can indicate that one of the main executive tasks is to establish and maintain relationships with leaders of other companies in order to have connections for creating partnerships and explore business opportunities when necessary.

The contact between managers can be fulfilled by being present in events such as conferences, commerce chambers meetings and other. Social interaction in sports practice, parties and voluntary work is also another viable approach to keep relations active. When partners are geographically distant, what is normal to VOs, virtual contact might take considerable importance by using chats, VoIP, email and others.

Katz and Kahn's [12] perspective that organizational structure is defined by cycles of events seems to be useful for VOs. Probably these firms have shorter cycles, with faster changes than in traditional ones. Long term structures would not be viable. Regarding to the authors systemic model, several characteristics such as import/export energy, processing and feedback might occur virtually, by means of IT. As the technology is prevalent, it seems to be a strong need for service level assurance in adequate levels to perform such tasks.

Emery and Trist [7] turbulent environment seem to be adequate to VOs. Fast changes in technology and economic conditions affect these companies dramatically. The lack of geographic constraints can lead to hypercompetitive markers [22]. In this context, the search for qualified professionals and the maintenance of some 
levels of organizational redundancy seems to be adequate. Technology clearly works in both Zuboff's [25] mechanisms: replacing human efforts and improving operational and informational and levels.

Regarding to contingency perspective, VO seem to have project like production. That is accomplished by teams that work to create a product or service. These products are sometime also digital goods, which mean that after the first item is produced, replication takes place with reduced costs. One important issue in contingency approach [24] is that it defines unitary production as been of low complexity. VO frequently face highly complex projects like research and development activities, which require qualified professionals to fulfill complex activities.

Regarding to Burns and Stalker [4] approach, it's possible to say that VOs are closer to the organic model which is adequate for turbulent environments. Virtual organizations are clearly different from mechanicist ones: decentralized authority, mutant worker responsibilities, lighter bureaucratic controls and horizontal structure. These characteristics are highly supported by means of Information Technology.

The table 1 below presents a synthesis of the organizational theories analyzed in the context of virtual organizations. It mainly indicates aspects where theories are convergent with VO and issues that aren't compatible.

Table 1. Virtual Organizations and Organizational Theories

\begin{tabular}{|c|c|c|c|}
\hline Virtual Org. & Theory & Convergent & Inadequate \\
\hline $\begin{array}{l}\text { Highly qualified } \\
\text { professionals }\end{array}$ & $\begin{array}{c}\text { Classic } \\
\text { Management }\end{array}$ & - & $\begin{array}{l}\text { Work specialization; } \\
\text { Centralized decisions; } \\
\text { Vertical hierarchy. }\end{array}$ \\
\hline $\begin{array}{l}\text { Structural } \\
\text { flexibility }\end{array}$ & $\begin{array}{l}\text { Power and } \\
\text { Authority }\end{array}$ & $\begin{array}{l}\text { Operational decisions taken } \\
\text { by workers. }\end{array}$ & $\begin{array}{l}\text { Dominant group interests in } \\
\text { organizational rules. }\end{array}$ \\
\hline $\begin{array}{l}\text { Work flexibility } \\
\text { Transparency }\end{array}$ & $\begin{array}{l}\text { Human } \\
\text { relations }\end{array}$ & $\begin{array}{l}\text { Informal relations among } \\
\text { members are encouraged. }\end{array}$ & $\begin{array}{l}\text { Informal interactions are not } \\
\text { perceived as means for } \\
\text { assuring power and control. }\end{array}$ \\
\hline $\begin{array}{l}\text { and governance } \\
\text { Proximity }\end{array}$ & Motivation & $\begin{array}{l}\text { Higher motivational levels; } \\
\text { Theory Y; Type B. }\end{array}$ & $\begin{array}{l}\text { Lower motivational levels; } \\
\text { Theory X; Type A. }\end{array}$ \\
\hline $\begin{array}{l}\text { among managers } \\
\text { and workers } \\
\text { Intense use of }\end{array}$ & Bureaucracy & Rational-legal system & $\begin{array}{l}\text { Explicit hierarchy; } \\
\text { Well defined work activities; } \\
\text { Hierarchy protecting } \\
\text { managers. }\end{array}$ \\
\hline $\begin{array}{l}\text { lntormation } \\
\text { technologies } \\
\text { Roles performed } \\
\text { by non-human } \\
\text { entities } \\
\text { Service level } \\
\text { requirements }\end{array}$ & Systems & $\begin{array}{l}\text { Virtual and non-human } \\
\text { interactions; } \\
\text { Cyclic structure; } \\
\text { Virtuality in energy flows, } \\
\text { processing and feedback; } \\
\text { Turbulent environment; } \\
\text { Levels of redundancy. }\end{array}$ & 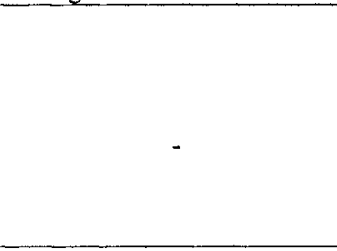 \\
\hline $\begin{array}{l}\text { Global operation } \\
\text { Virtual controls }\end{array}$ & Contingency & $\begin{array}{l}\text { Decentralization; } \\
\text { Horizontal structure; } \\
\text { Organic organizations. }\end{array}$ & $\begin{array}{l}\text { Unitary production with low } \\
\text { complexity; } \\
\text { Mechanic organizations. }\end{array}$ \\
\hline
\end{tabular}




\section{Conclusions}

Virtual organizations are different from the ones studied by several organizational theory researchers. Classic management and human relations are almost completely inadequate to study VO but bureaucratic theory has still some useful characteristics if it's known that its implementation takes place with virtual characteristics.

Contemporary approaches are better for understanding virtual organizations. Motivational and leadership theories use perceive the human in a suitable way to virtual organization workers. However, two components are not present in these approaches: high turnover rates and the constant interaction between organization and worker by means of technology.

Decision making in virtual organizations is more decentralized, especially regarding to operational issues. One issue that could be focus of future research is to check if and how strategic decisions are taken in VOs.

Systems theory offers good mechanisms for understanding VOs. The characteristics and impacts on organization and workers of the interactions between human and non-human entities are important research issues that should be addressed.

Still an extremely affected point in VO's approach is enterprise strategy. All traditional theories explain the strategy concept like a combination of two factors: the competition and the customers, both characterized to an external view. They are stipulated as the essential base for the development of a competitive strategy. But in VOs occurs that both support ideas, the slight knowledge of market and space, are completely diffuse for the virtual organizations.

In this context, tracking information regarding to current and potential competitors is a very difficult task. Mapping external changes is also critical to understand customer behaviour. This is extremely complicated due to the lack of knowledge on the customer space neither customer control. However, the VO is always exposed, in special in its critical resources and capacities for the organizational performance.

Therefore, while in the traditional organizational theory processes are stipulated to assure the competitive advantage with environmental guide tactics for VOs this is an integrated process and part of the chain of communication of the ordinary activity, an essentially technological procedure anchored in highly qualified professionals and intense use of IT means.

The information technology influence on business processes seems to be increasing. Several processes are migrating to be completely fulfilled without human interaction. What are the organizational consequences of this tendency? The requirement of higher service levels might be one possible outcome.

The existence of unitary production, almost like projects with highly complex tasks is an important issue where contingency-based approaches are frontally defied. This characteristic can generate important impacts in virtual organizations, such as stronger decentralization of decision making, new structure designs and the increment in productivity.

As it was made clear in this paper, virtual organizations aren't compatible with classic management theories. Contemporary approaches might be useful but there 
are important gaps that deserve further investigation. One interesting next step could be the development of a broad characterization framework to virtual organizations, and then start exploring the unclear issues.

\section{References}

1. 1.Alexander, Rodney, New York's Engineering and Technically Skilled Labor, 1999.

2. 2.C. Argyris, Personality and organization (Harper \& Row, New Your, 1957).

3. 3.P. Blau, The dynamics of bureaucracy (University of Chicago Press, Chicago, 1955).

4. 4.T. Burns, G. M. Stalker, The management of innovation (Tavistock, 1961).

5. 5.C. B. Cano, J. L. Becker, H. M. R. Freitas, Organizações no Espaço Cibernético, Revista de Administração de Empresas Eletrônica, v. 1, n. 1 (2002).

6. 6.W. H. Davidow, M. S. Malone, The Virtual Corporation : Structuring and Revitalizing the Corporation for the 21st Century (Collins, 1993).

7. 7.F. Emery, E. Trist, The causal texture of organizational environments, Human Relations, v. XVIII (1965).

8. 8.H. Fayol, Administration industrielle et générale (Dunod, Paris, 1916).

9. 9.S.L. Goldman, R. N. Nagel, K. Preiss, Agile competitors and virtual organizations: Strategies for enriching the customer (Thomson Publishing, New York, 1995).

10. 10.A. Gouldner, Patterns of industrial bureaucracy (Free Press, Glencoe, 1954).

11. 11.R. Hale, P. Whitlaw, Towards the virtual organization (McGraw-Hill, London, 1997).

12. 12.D. Katz, R. L. Kahn, Psicologia social das organizações (Atlas, São Paulo, 1970).

13. 13.R. Likert, New patterns of management (McGraw-Hill, New York, 1961).

14. 14.A. Maslow, A theory of human motivation, Psychological Review, v.50, 370-96 (1943).

15. 15.E. Mayo, The human problems of an industrial civilization (Macmillan, New York, 1933).

16. 16.D. Mcgregor, The human side of enterprise, in: Leadership and motivation: essays of Douglas McGregor, edited by W. Bennis, E. Schein (MIT Press, Cambridge, 1966).

17. 17.R. Merton, The role-set: problems in sociological theory, British Journal of Sociology, v.VIII, p. 106-120(1950).

18. 18.H. Mintzberg, A. Mchugh, Strategy Formation in an Adhocracy, Administrative Science Quarterly, v. 30(2), 160-197 (1985).

19. 19.A. Mowshowitz, Virtual organization, Communications of the ACM, v. 40(9), 30-37 (1997).

20. 20.F. Taylor, The Principles of scientific management (WW. Norton \& Co, New York, 1911). Available at: <http://www.gutenberg.org/etext/6435>.

21. 21.N. Venkatraman, J. C. Henderson, Real strategies for virtual organizing, Sloan Management Review, v. 29(2), 33-47 (1998).

22. 22.H. W. Volberda, Toward the Flexible Form: How to Remain Vital in Hyper competitive Environments, Organization Science, v. 7(4), 359-374 (1996).

23. 23.M. Weber. Bureaucracy, in: Max Weber: Essays in Sociology edited by H. Gerth and C. W. Mills (Oxford, New York, 1946).

24. 24.T. Reeves, J. Woodward, Industrial organization, behavior and control (Oxford University Press, Oxford, 1970).

25. 25.S. Zuboff, In the age of the smart machine: the future of work and power (BasicBooks, New York, 1988). 